\title{
IgG4-Related Tubulointerstitial Nephritis and Lymphadenopathy after Therapy for Malignant Lymphoma
}

\author{
Yasuko Oshima ${ }^{1}$, Ryosuke Usui ${ }^{1}$, Shun Manabe ${ }^{1}$, Naoki Hasegawa ${ }^{2}$, Yukio Kakuta ${ }^{2}$, \\ Kosaku Nitta ${ }^{3}$ and Michiyasu Hatano ${ }^{1}$
}

\begin{abstract}
We report a middle-aged Japanese man who had a past history of malignant lymphoma with tubulointerstitial nephritis (TIN) presenting a high serum immunoglobulin G4 (IgG4) concentration and bilateral kidney enlargement and swelling of many lymph nodes. Although lymph node biopsy was not evident of a recurrence of lymphoma, kidney biopsy showed prominent infiltration of IgG4-positive plasma cells in a tubulointerstitial lesion but not in glomeruli. We made a diagnosis of IgG4-related TIN and lymphadenopathy; administration of oral prednisolone improved his physical and laboratory parameters. This is the first report of a case of IgG4-related TIN and lymphadenopathy after therapy for malignant lymphoma.
\end{abstract}

Key words: IgG4-related disease, tubulointerstitial nephritis, lymphadenopathy, malignant lymphoma,

Henoch-Schönlein purpura

(Intern Med 51: 1221-1226, 2012)

(DOI: 10.2169/internalmedicine.51.6691)

\section{Introduction}

In this decade, the new concept of disease, termed IgG4related disease, characterized by a high concentration of serum IgG4 and marked infiltration of IgG4-postive cell into several organs, was proposed. The first report of this disease by Hamano et al. in 2001 (1) described it as sclerosing pancreatitis with elevated serum IgG4 concentration; it triggered numerous subsequent reports. Now, the same disease spectrum of IgG4-related complications has been expanded to contain many diseases such as autoimmune pancreatitis (1), sclerosing cholangitis (2), autoimmune hepatitis (3), Mikulicz's disease/chronic sialadenitis $(4,5)$, idiopathic retroperitoneal fibrosis (6), prostitis (7), hypophysitis (8), noninfectious aortitis (9), pulmonary disease (10), lymphadenopathy (11), and TIN (12-17). Thus, the clinical features of IgG4-related disease were seen in many extra-pancreatic organs rather than in just localization to the pancreas. Although IgG4 might play a key role in the pathogenesis of these diseases, how $\operatorname{IgG} 4$ is involved in these disorders is still unclear.

\section{Case Report}

A 41-year-old Japanese man was admitted to our hospital in 1996 because of right lower abdominal pain. Colonoscopy revealed a tumor large enough to cause intestinal obstruction, and then endoscopic biopsy revealed malignant lymphoma (follicular cell lymphoma). Surgical resection of a colon tumor and chemotherapy of six courses of THPCOP, were carried out; he attained clinical complete remission in 1997. From the summer of 2007, purpura that tended to disappear in a few days occurred in his leg repeatedly. In May 2009 he was admitted to hematology because of cervical and inguinal lymphnode swelling. He was suspected to have a recurrence of malignant lymphoma. In July he was referred to our nephrology division from hematology for the evaluation of mild renal dysfunction with hypertension and lower leg purpura. In August skin biopsy was con-

${ }^{1}$ Department of Medicine, Division of Nephrology, Yokohama Rosai Hospital, Japan, ${ }^{2}$ Department of Pathology, Yokohama Rosai Hospital, Japan and ${ }^{3}$ Department of Medicine, Kidney Center, Tokyo Women's Medical University, Japan

Received for publication October 10, 2011; Accepted for publication January 9, 2012

Correspondence to Dr. Ryosuke Usui, fzk11643@nifty.com 

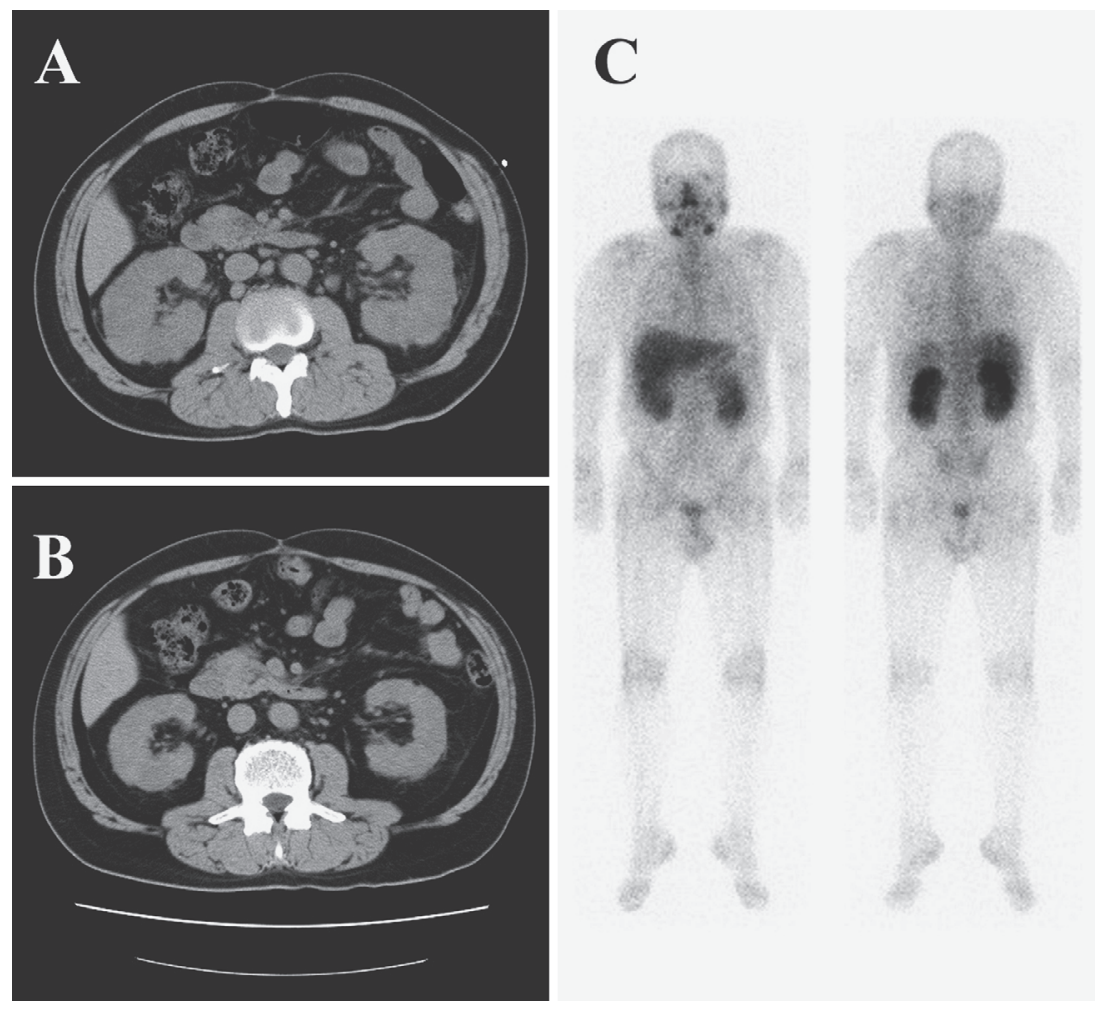

Figure 1. CT scan at kidney level before therapy (A) and 4 months after therapy (B). Gallium citrate scintigraphy $(\mathrm{C})$.

ducted, it revealed Henoch-Schönlein purpura (HSP). In October although a lymph node biopsy was carried out, it did not reveal a malignant lymphoma. Renal biopsy was planned because of bilateral kidney enlargement by CT scan and gradually elevating serum creatinine level, however, the examination was delayed two times due to hospitalizations with ventricular tachycardia (VT) and epididymitis, respectively. Catheter ablation for arrhythmia resulted in sinus rhythm, and antibiotic cured epididymitis. Renal biopsy was performed in January 2010.

On physical examination at the first hospitalization to our department, he had blood pressure of $166 / 103 \mathrm{mmHg}$ and no fever. There was no hypertensive disorder in ocular fundus. A right cervical and inguinal lymphnodes were palpable without tenderness, and no abnormal findings were seen in chest. An operation scar was seen in right lower abdomen. Neurological findings were almost intact. Purpura was not identified on the extremities, but pigmentation in lower limbs was seen.

Laboratory examinations showed the following results: WBC $11,900 / \mu \mathrm{L}$, red blood cell $422.0 \times 10^{4} / \mu \mathrm{L}, \mathrm{Hb} 12.5 \mathrm{~g} /$ $\mathrm{dL}$, Platelet $25.7 \times 10^{4} / \mu \mathrm{L}$, total protein $9.0 \mathrm{~g} / \mathrm{dL}$, albumin 3.3 $\mathrm{g} / \mathrm{dL}$, aspartate aminotransferase $19 \mathrm{IU} / \mathrm{L}$, alanine aminotransferase $12 \mathrm{IU} / \mathrm{L}$, lactate dehydrogenase $241 \mathrm{IU} / \mathrm{L}$, amylase $148 \mathrm{IU} / \mathrm{L}$, blood urea nitrogen $26.2 \mathrm{mg} / \mathrm{dL}$, creatinine $1.74 \mathrm{mg} / \mathrm{dL}, \mathrm{Na} 137 \mathrm{mEq} / \mathrm{L}, \mathrm{K} 4.3 \mathrm{mEq} / \mathrm{L}, \mathrm{Cl} 105$ $\mathrm{mEq} / \mathrm{L}$, C-reactive protein $1.47 \mathrm{mg} / \mathrm{dL}, \operatorname{IgG} 4,858 \mathrm{mg} / \mathrm{dL}$, IgG subclasses; IgG1 2,420 mg/dL, IgG2 $1,240 \mathrm{mg} / \mathrm{dL}$, IgG3 $441 \mathrm{mg} / \mathrm{dL}, \operatorname{IgG} 41,590 \mathrm{mg} / \mathrm{dL}$, IgM $13 \mathrm{mg} / \mathrm{dL}, \operatorname{IgA}$ $147 \mathrm{mg} / \mathrm{dL}, \mathrm{CH} 50<10 \mathrm{U} / \mathrm{mL}, \mathrm{C} 334.8 \mathrm{mg} / \mathrm{dL}, \mathrm{C} 4$ undetect- able, anti-nuclear antibody $\times 160$, anti-Ro/SS-A antibody (Ab.) negative, anti-La/SS-B Ab. negative, $M$ protein negative, soluble interleukin-2 receptor 2,380 U/mL, interleukin$62.35 \mathrm{pg} / \mathrm{mL}$, cryoglobulin negative, anti-hepatitis B surface antigen negative, anti-hepatitis $\mathrm{C}$ Ab. negative, anti-human immunodeficiency virus $\mathrm{Ab}$. negative, Epstein-Barr virus capsid antigen $($ EBVCA)-IgG $\times 320$, EBVCA-IgM undetectable, EBVCA-IgA undetectable, EBV nuclear antigen antibody undetectable, urinary protein $0.25 \mathrm{~g} / \mathrm{day}, \alpha 1-$ microglobulin $35.25 \mathrm{mg} /$ day, Bence-Jones protein negative, urinary sediments: red blood cell $<1 / \mathrm{HF}$, WBC $<1 / \mathrm{HF}$, K-ras gene mutation in surgical resected colon tumor in 1996 and lymphadenopathy in 2010 undetectable.

Computed tomography (CT) scan showed bilateral kidney enlargement with irregular surface (Fig. 1A) and lymph node swelling of paraaortic, common iliac, bilateral inguinal and axillary lesion. Submandibular gland also seemed to be slightly swelling. No abnormal findings were seen in pancreas and retroperitoneum. Gallium citrate scintigraphy showed gallium-67 accumulation in the bilateral kidney, but not in pancreas, lymphnodes, submandibular gland, lacrimal gland or salivary gland (Fig. 1C).

Pathological findings of the surgical resected specimen in 1996 are shown in Fig. 2. The specimen for light microscopy revealed follicular formation and infiltration of small lymphoid cells (Fig. 2A, B). Immunohistochemistry (IHC) showed positivity for CD20 (Fig. 2C) and negativity for UCHL (Fig. 2D), hence these findings concluded the diagnosis follicular cell lymphoma.

Skin biopsy identified leukocytoclastic vasculitis accom- 


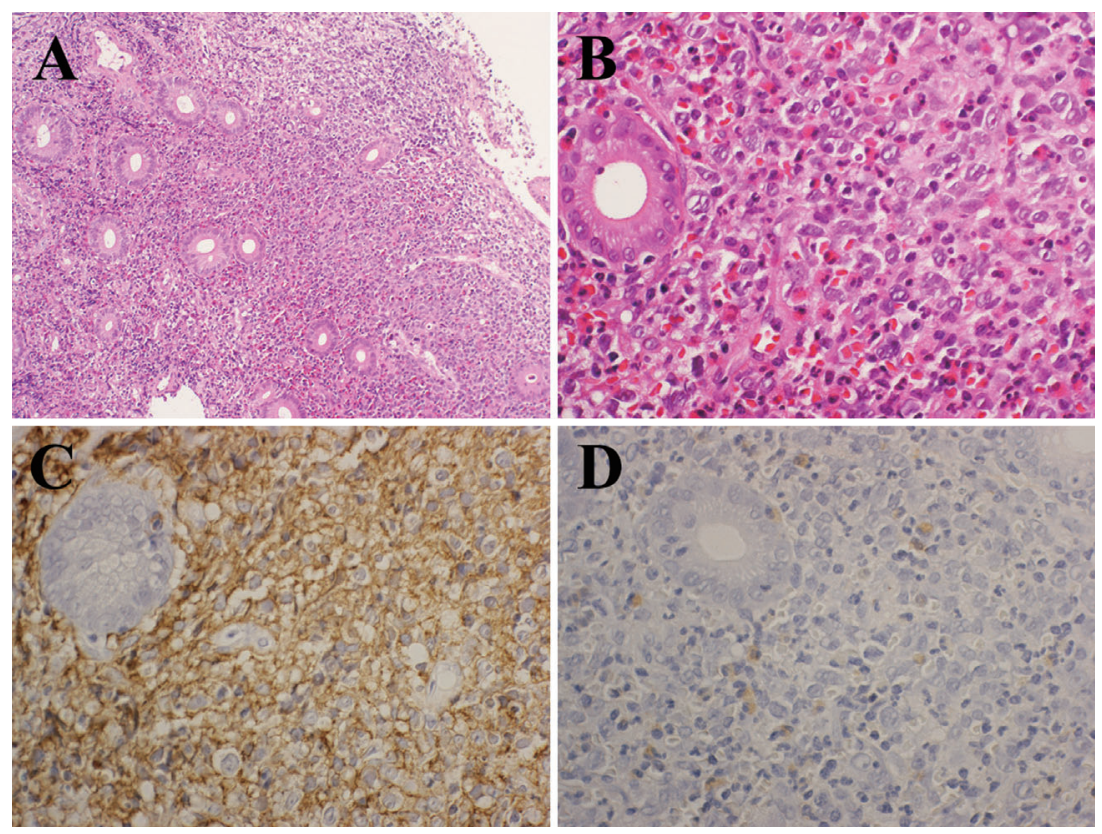

Figure 2. Microscopic findings of a surgical specimen in 1996. Infiltration of numerous small lymphoid cells $(\mathrm{A} \times 100, \mathrm{~B} \times 400)$. IHC for CD20 $(\mathrm{C} \times 400)$ and for UCHL $(\mathrm{D} \times 400)$.

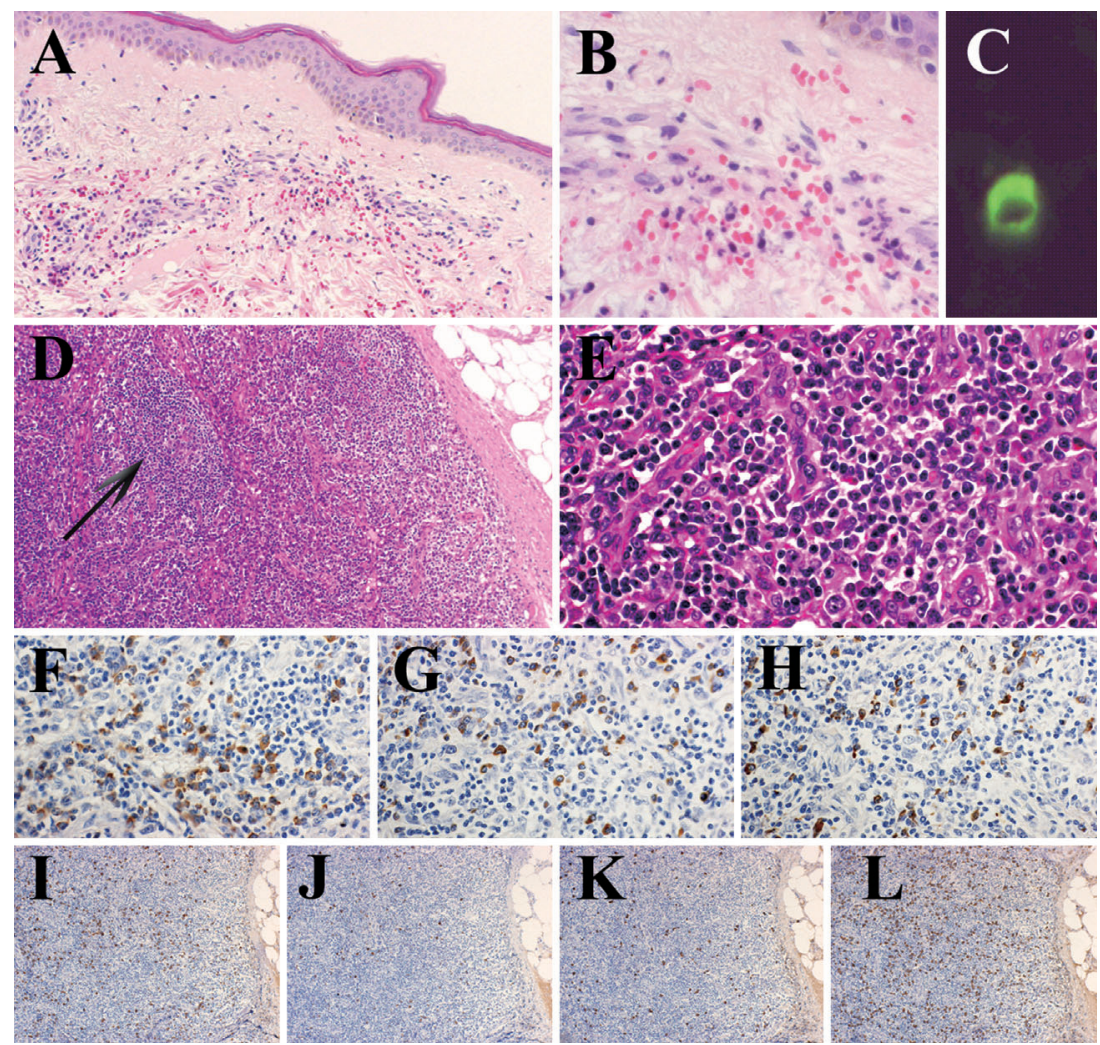

Figure 3. Skin biopsy and lymphnode biopsy in 2009. Skin biopsy for light microscopy with Hematoxylin and Eosin staining (H.E. stain) $(\mathrm{A} \times 100, \mathrm{~B} \times 400)$, and for IF for IgA (C). Lymphnode biopsy for light microscopy with H.E. stain $(\mathrm{D} \times 100$, arrowhead indicates lymphoid follicle, $\mathrm{E} \times 400)$. IHC for IgG $(\mathrm{F} \times 400)$, light-chain kappa $(\mathrm{D} \times 400)$ and lambda $(\mathrm{E} \times 400)$. Retrospective stains for IgG subclasses (I: IgG1, J: IgG2, K: IgG3, L: IgG4,×100).

panied by deposition of $\operatorname{IgA}$ and $\mathrm{C} 3$ in vascular wall (Fig. 3A-C), consistent with Henoch-Schönlein purpura (HSP). From October 2009, purpura gradually decreased without any treatment.
Lymph node biopsy in 2009 showed follicle formation and abundant plasma cell infiltration with hematoxylin and eosin stain (Fig. 3D, E), but lymphoid cell infiltration was not evident. IHC showed that almost every plasma cell was 


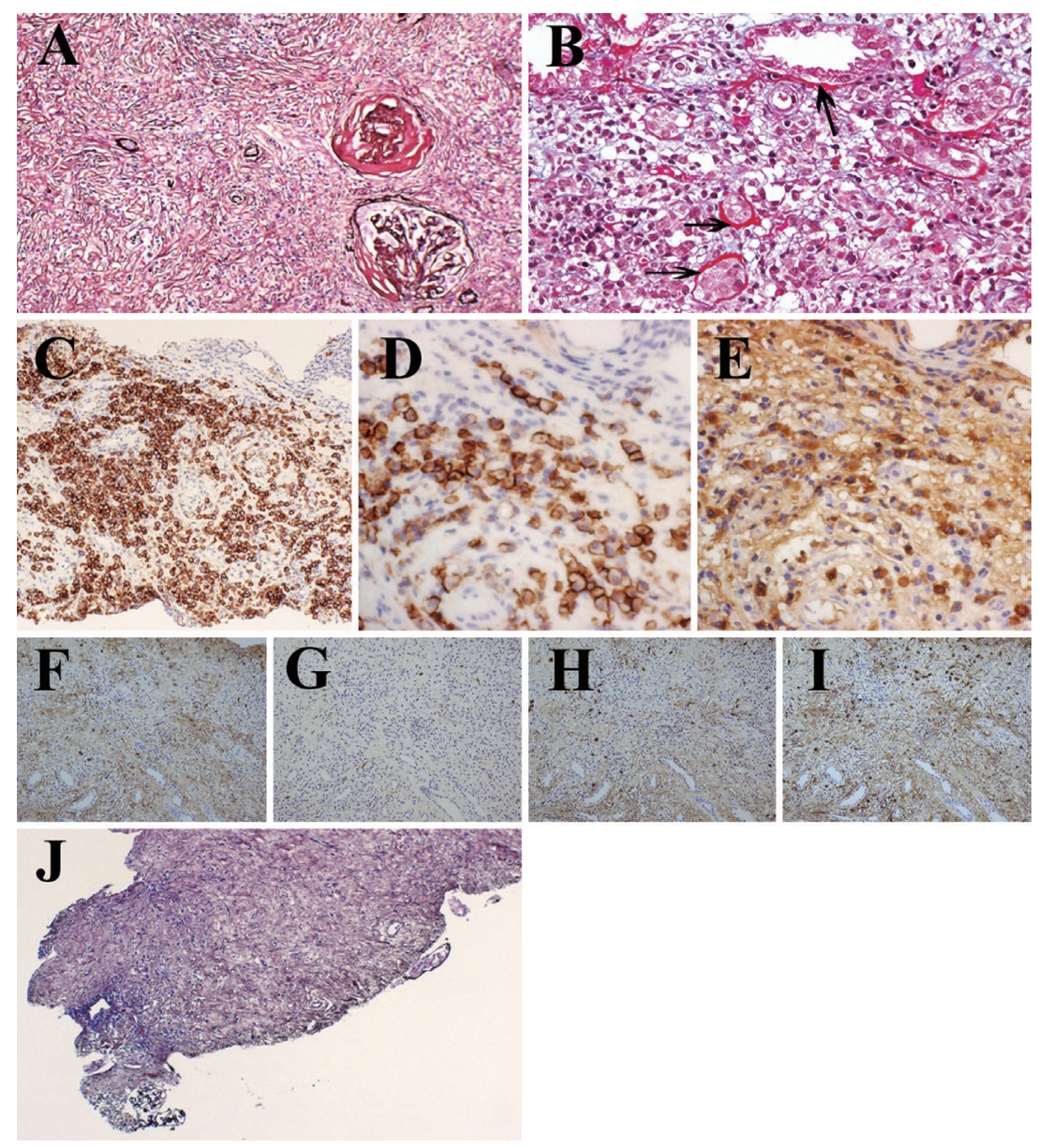

Figure 4. Renal biopsy for light microscopy (A: periodic acid methenamine silver stain $($ PAM $) \times 100$, B: trichrome stain, $\times \mathbf{2 0 0}$, arrowhead indicates linear reddish deposit along TBM). IHC for CD138 (C×100). IHC for CD138 and IgG4 in serial section (D×400, E×400). IHC for IgG and IgG subclasses (F: IgG1, G: IgG2, H: IgG3, I: IgG4, ×100). Renal re-biopsy for light microscopy (J: PAM stain $\times 100$ ).

positive for IgG (Fig. 3F) and had no light-chain monoclonality (Fig. 3G, H). Retrospective stain for $\mathrm{IgG}$ subclasses, IgG1-4, showed that IgG4 positive cell crowded more than others (Fig. 3I-L).

Pathological findings of the renal biopsy are shown in Fig. 4. The specimen for light microscopy contained 11 glomeruli with 3 global glomerulosclerosis. Mesangial proliferation and a change of glomerular basement membrane thickness were not evident. Severely atrophic tubules and widespread interstitial fibrosis, typical fibrosis so-called storiform appearance, were observed (Fig. 4A). Trichrome stain revealed linear reddish deposit along the tubular basement membrane (Fig. 4B). In tubulointerstitial lesion diffuse marked infiltration of CD138 positive plasma cells was observed (Fig. 4C). The stains of CD138 and $\mathrm{IgG} 4$ in serial sections revealed that $>40 \%$ plasma cells are positive for IgG4 and >10 IgG4-positive cells/high power field (Fig. 4D, E). IHC revealed numerous IgG1- and IgG4positive plasma cells and tubule basement membrane (TBM) (Fig. 4F-I). On the other hand, IgG staining and the other stainings, such as $\operatorname{IgA}$, IgM, C3 and C4, were not evident in glomeruli (data not shown). Electron microscopy showed fine granular electron dens deposits in the tubulointerstitial lesion around the plasma cells (data not shown).

Finally, we made a diagnosis of IgG4-related TIN on the basis of diagnostic criteria (18) and lymphadenopathy. Oral prednisolone at an initial dose of $40 \mathrm{mg} /$ day was administered from January 2010. Two months after therapy, his serum creatinine, $\mathrm{IgG}$ and $\mathrm{IgG} 4$ had decreased to $1.32 \mathrm{mg} / \mathrm{dL}$, $797 \mathrm{mg} / \mathrm{dL}$ and $260 \mathrm{mg} / \mathrm{dL}$, respectively. Three months after therapy, we confirmed that the kidney size was becoming smaller by CT scan (Fig. 1B). Renal re-biopsy performed six months after therapy showed reduced number of infiltrated plasma cells, but expressed strong fibrosis (Fig. 4J). One year after therapy, serum creatinine level was maintained at about $1.3 \mathrm{mg} / \mathrm{dL}$.

\section{Discussion}

Approximately 10 years after the first report of IgG4related disease accumulated reports are now evident that this disease is a multiple organ disorder and has a variety of 


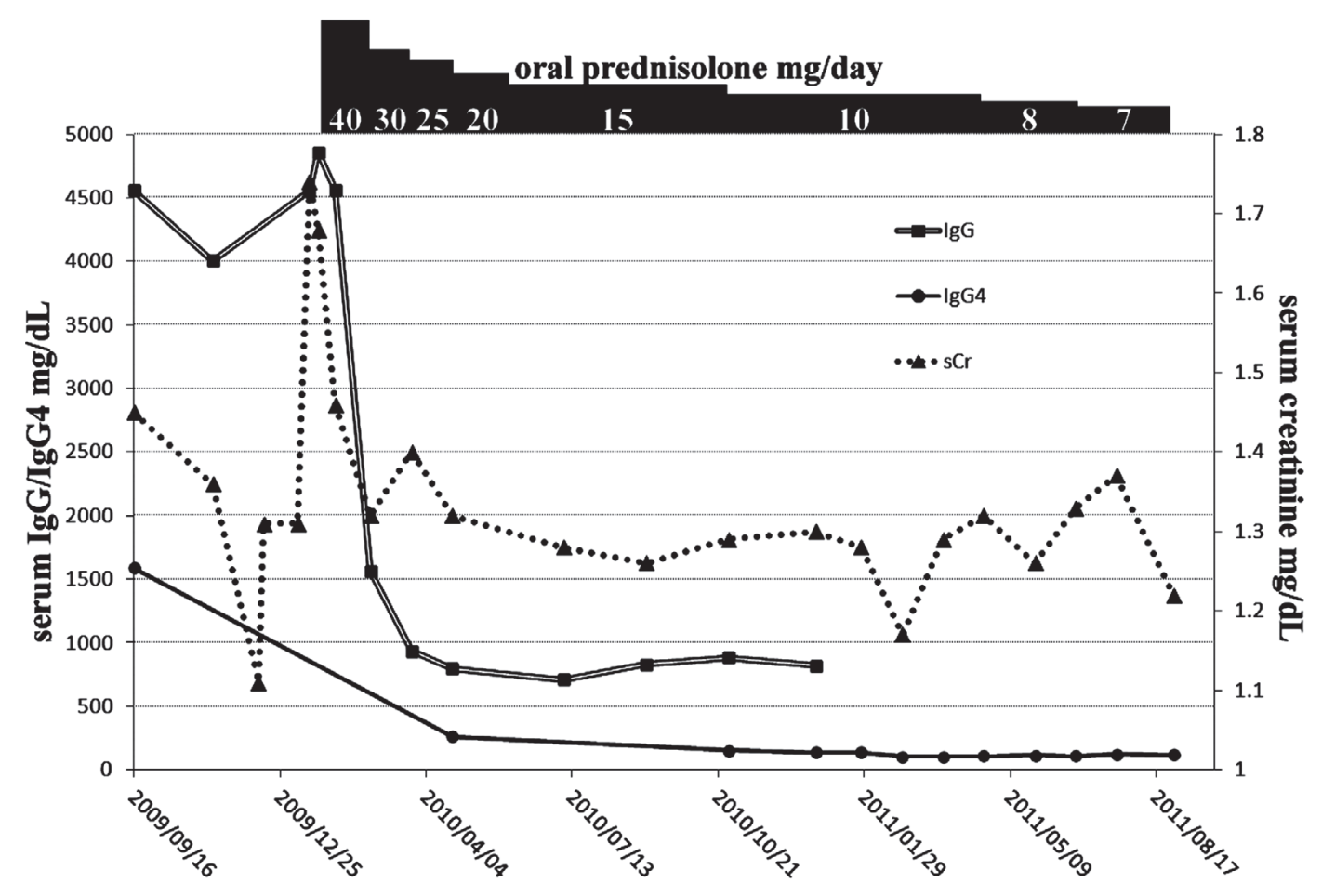

Figure 5. Clinical course.

clinical features in individual cases. Many case reports have been published, however, in all cases common symptoms or laboratory parameters have not been discovered except for a high serum concentration of $\mathrm{IgG}$ and $\mathrm{IgG} 4$, therefore sometimes it seems that clinicians are struggling to make the diagnosis. In the present case, various symptoms, HSP, VT, epididymitis, lymphadenopathy and TIN, occurred in the clinical course. Although we could not confirm whether these symptoms occurred in a IgG4-dependent manner, we think these symptoms and past history of malignant lymphoma delayed the diagnosis and therapy.

Recently Saeki et al. published a paper in which the clinical features of IgG4-related TIN, including their cases, were described (17). It is said that TIN is one of the popular symptoms of IgG4-related disease, but in general cases of TIN undergoing renal biopsy regardless of its causes seem to be relatively rare because of its trivial urinary findings. Initially we supposed a cause of his mild renal dysfunction was due to hypertensive nephrosclerosis because of a relatively longstanding history of hypertension and poor urinary findings, whereas Henoch-Schönlein purpura nephritis (HSPN) was not suspected strongly because purpura was seen in the lower legs but it was not an evident abnormality in urinary findings.

After lymph node biopsy his lymph node swelling was thought to be possibly multicentric Castleman's disease (MCD). But his clinical features, atypical pathological findings and non-elevated CRP and IL-6 and no anemia were not suitable for diagnosis of MCD. Renal dysfunction is one of major long-term complications of Castleman's disease, but its cause has not been clarified yet. Not all patients of Castleman's disease receive treatment with a steroid, how- ever, some of the patients diagnosed as Castleman's disease who yielded a prompt response with steroid therapy might have been possibly IgG4-related disease (11). In the relationship between IgG4-related disease and malignant lymphoma, Sato et al. reported a case of IgG4-producing retroperitoneal lymph node in a patient of marginal zone B-cell lymphoma (19). The present case, however, is different from this case in point of histological findings and no light-chain monoclonality. Moreover, malignant lymphoma and IgG4related disease of our case developed in different periods clearly. We think that there is no association between IgG4related complications and malignant lymphoma in our case.

Recently, cases of combined IgG4-related disease and microvasculitis, including HSP/HSPN, have been reported $(20,21)$. HSP of the present case was diagnosed histologically. Depositions of IgA and C3 in small arterioles of dermis were identified, but not in glomeruli. Tamai et al. (21) discussed the possibility of association between HSP/HSPN and IgG4-related disease and that repetitious purpura might lead to IgG4-related disease. There's no doubt in the present case that HSP preceded IgG4-related disease about for two years. On the other hand, it's known that a morbidity of HSP seems to be predominantly higher than IgG4-related disease and combined case of the two is not common. To confirm the association of two diseases, we think that further accumulation of cases is necessary.

Furthermore VT and epididymitis occurred in the present case's clinical course. We have a great interest in whether these events were part of IgG4-related disease, but regretfully we have no evidence to prove these associations. A relationship between VT, epididymitis, and IgG4-related disease has not been reported. Additively, CT scan showed 
slightly swelling submandibular gland, but gallium citrate scintigraphy did not reveal significant gallium-67 accumulation in this gland.

Recently Kamisawa et al. reported that K-ras gene mutation is detected in some AIP patients (22). Ras proteins, GTP-coupled proteins, contribute to the signaling of cell proliferation and transformation, and so forth. In general, mutations in the Ras protein cause constitutive activation of Ras GTPase without any signaling from upstream of Ras, resulting in cell proliferation, such as tumorigenesis. K-ras gene mutation may explain the pathogenesis and mechanism of IgG4-related disease in some cases, however, in the present case K-ras gene mutation was not evident in both specimens, malignant lymphoma and IgG4-related lymphadenopathy.

Usually corticosteroid therapy is very effective for clinical symptoms and laboratory parameters in IgG4-related disease. Unfortunately the serum creatinine level was elevated to $1.74 \mathrm{mg} / \mathrm{dL}$ at the time of renal biopsy, however, corticosteroid therapy improved renal function, lymph node swelling and serum IgG level. Previous reports indicated that tissue infiltrated by IgG4-producing cells has been accompanied by strong fibrosis, so that long-term prognosis has been unknown. It is important to bear in mind that early diagnosis and treatment is desirable in IgG4-related disease.

The authors state that they have no Conflict of Interest (COI).

\section{References}

1. Hamano H, Kawa S, Horiuchi A, et al. High serum IgG4 concentrations in patients with sclerosing pancreatitis. $\mathrm{N}$ Engl $\mathrm{J}$ Med 344: 732-738, 2001.

2. Hamano H, Kawa S, Uehara T, et al. Immunoglobulin G4-related lymphoplasmacytic sclerosing cholangitis that mimics infiltrating hilar cholangiocarcinoma: part of a spectrum of autoimmune pancreatitis? Gastrointest Endosc 62: 152-157, 2005.

3. Kamisawa T, Funata N, Hayashi T, et al. A new clinicopathological enity of IgG4-related autoimmune disease. J Gastroenterol 38: 982-984, 2003.

4. Yamamoto M, Harada S, Ohara M, et al. Clinical and pathological differences between Mikulicz's disease and Sjögren's syndrome. Rheumatology 44: 227-234, 2005.

5. Geyer JT, Ferry JA, Harris NL, et al. Chronic sclerosing sialadenitis (Küttner Tumor) is an IgG4-associated disease. Am J Surg Pathol 34: 202-210, 2010.

6. Hamano H, Kawa S, Ochi Y, et al. Hydronephrosis associated with retroperitoneal fibrosis and sclerosing pancreatitis. Lancet
359: 1403-1404, 2002.

7. Nishimori I, Kohsaki T, Onishi S, et al. IgG4-related autoimmune prostatitis: two cases with or without autoimmune pancreatitis. Intern Med 46: 1983-1989, 2007.

8. Nishioka H, Shibuya M, Haraoka J. Immunohistochemical study for IgG4-positive plasmacytes in pituitary inflammatory lesions. Endocr Pathol 21: 236-241, 2010.

9. Stone JH, Khosroshahi A, Hilgenberg A, Spooner A, Isselbacher EM, Stone JR. IgG4-related systemic disease and lymphoplasmacytic aortitis. Arthritis Rheum 60: 3139-3145, 2009.

10. Takato H, Yasui $M$, Ichikawa $Y$, et al. Nonspecific interstitial pneumonia with abundant IgG4-positive cells infiltration, which was thought as pulmonary involvement of IgG4-related autoimmune disease. Intern Med 47: 291-294, 2008.

11. Sato Y, Kojima M, Takata K, et al. Systemic IgG4-related lymphadenopathy: a clinical and pathologic comparison to multicentric Castleman's disease. Mod Pathol 22: 589-599, 2009.

12. Takeda S, Haratake J, Kasai T, et al. IgG4-associated idiopathic tubulointerstitial nephritis complicating autoimmune pancreatitis. Nephrol Dial Transplant 19: 474-476, 2004.

13. Saeki T, Nishi S, Ito $T$, et al. Renal lesions in IgG4-related systemic disease. Intern Med 46: 1365-1371, 2007.

14. Yoneda K, Murata K, Katayama K, et al. Tubulointerstitial nephritis associated with IgG4-related autoimmune disease. Am J Kidney Disease 50: 455-462, 2007.

15. Saeki T, Saito A, Yamazaki H, et al. Tubulointerstitial nephritis associated with IgG4-related systemic disease. Clin Exp Nephrol 11: 168-173, 2007.

16. Cornell LD, Chicano SL, Deshpande V, et al. Pseudotumors due to IgG4 immune-complex tubulointerstitial nephritis associated with autoimmune pancreatocentric disease. Am J Surg Pathol 31: 1586-1597, 2007.

17. Saeki T, Nishi S, Imai N, et al. Clinicopathological characteristics of patients with IgG4-related tubulointerstitial nephritis. Kidney Int 78: 1016-1023, 2010.

18. Kawano M, Saeki T, Nakashima H, et al. Proposal for diagnostic criteria for IgG4-related kidney disease. Clin Exp Nephrol 15: 615-626, 2011.

19. Sato $\mathrm{Y}$, Takata $\mathrm{K}$, Ichimura $\mathrm{K}$, et al. IgG4-producing marginal zone B-cell lymphoma. Int J Hematol 88: 428-433, 2008.

20. Naitoh I, Nakazawa T, Ohara $H$, et al. Autoimmune pancreatitis associated with various extrapancreatic lesions during a long-term clinical course successfully treated with azathioprine and corticosteroid maintenance therapy. Intern Med 48: 2003-2007, 2009.

21. Tamai R, Hasegawa $Y$, Hisano S, Miyake $K$, Nakashima $H$, Saito T. A case of IgG4-related tubulointerstitial nephritis concurrent with Henoch-Schönlein purpura nephritis. Allergy Asthma Clin Immunol 7: 5, 2011.

22. Kamisawa T, Horiguchi S, Hayashi $Y$, et al. K-ras mutation in the major duodenal papilla and gastric and colonic mucosa in patients with autoimmune pancreatitis. J Gastroenterol 45: 771-778, 2010.

(C) 2012 The Japanese Society of Internal Medicine http://www.naika.or.jp/imindex.html 